\title{
The influence of Social Support and Personal Networks on Doctoral Student Performance
}

\author{
Valentina Hlebec ${ }^{1}$, Tina Kogovšek ${ }^{2}$, and Anuška Ferligoj ${ }^{1}$
}

\begin{abstract}
In the paper the effects of individual and social factors on the performance of doctoral students (young researchers) in Slovenia are studied. The paper starts with an overview of theoretical models and empirical studies that originate in educational research and psychological research. The paper continues with a description of theoretical models and empirical studies that originate from organizational research and focus on explaining job performance. The Job Demands-Resources model (Xanthopoulou et al., 2007; Bakker and Demerouti, 2007) is used to explain why some doctoral students perform better than others. Social support networks and social support from a doctoral student's research group (supervisor and co-workers) are operationalized as job resources. The proportion of explained variance of the doctoral students' academic performance is 0.14 . Social support and personal networks have the largest effect, following by work motivation.
\end{abstract}

\section{Introduction}

In the paper the effects of individual and social factors on the performance of doctoral students (young researchers) in Slovenia are studied. Young researchers are a special group of doctoral students in Slovenia and obtain a long-term $(2.5-$ 3.5 years) government scholarship ${ }^{3}$ to achieve their doctoral degree. They are supervised by experienced senior researchers. The role of supervising a young researcher is first assigned to a senior researcher on the basis of the senior researcher's academic performance and already established skills as a research manager. The best candidate is then selected for the young researcher position on the basis of their academic performance at the undergraduate level. Most often, a young researcher joins the senior researcher's research group to pursue a specific

\footnotetext{
${ }^{1}$ University of Ljubljana, Faculty of Social Sciences, Kardeljeva ploščad 5, SI-1000 Ljubljana, Slovenia.

${ }^{2}$ University of Ljubljana, Faculty of Arts, Aškerčeva 2/Faculty of Social Sciences, Kardeljeva ploščad 5, SI-1000 Ljubljana, Slovenia.

3 Conditions and regulations can be found at ARRS (2011), URL: http://www.arrs.gov.si/sl/akti/prav-sof-ocen-sprem-razisk-dej-260111.asp.
} 
research question. The performance of doctoral students or young researchers ${ }^{4}$ can be conceptualized on one hand as an educational outcome, usually operationalized with a cumulative grade average or intention not to "drop out". In this respect, one can rely on theories and models originating from educational research in order to find the determinants of educational performance, especially focusing on the university level. On the other hand, doctoral students who are also young researchers have a work contract and are employed at the university. Their performance can be conceptualized as a job outcome, which is again operationalized in different ways, e.g. as specific task completion, job satisfaction, burnout and the intention of taking another job. Therefore, we can also look for an explanation of doctoral students' success in the field of organizational research.

We try to combine both interpretations of doctoral students' positions (education at the graduate level as well as a job) to examine possible factors that influence their performance. The paper starts with an overview of theoretical models and empirical studies that originate in educational research and psychological research. We argue that current research acknowledges the importance of motivation to predict an educational performance and overlooks the possible influences of the social environment on educational performance. Apart from very few exceptions, interactional measures of social support and personal networks were omitted from explanatory models in previous studies. This may account for the lack of predictive power of perceptive measures of general social support and social involvement to explain educational outcomes. The paper continues by describing theoretical models and empirical studies that originate from organizational research and focusing on explaining job performance. We will employ the Job Demands-Resources model (Xanthopoulou et al., 2007; Bakker and Demerouti, 2007) to explain why some doctoral students perform better than others. Social support networks and social support from a doctoral student's research group (supervisor and co-workers) are operationalized as job resources.

Utilizing specific findings from the fields of education and organization, we test the influence of doctoral students' work motivation and specific job resources (social support and personal networks oriented towards thesis completion) on their performance, controlling for years spent in the institution. Implications for further research are also outlined and discussed.

\section{Predicting educational outcomes (academic performance)}

A large number of studies examine the correlates or determinants of educational outcomes, most often distinguishing between performance (usually an overall or

\footnotetext{
${ }^{4}$ In Slovenia, the official name of a doctoral student receiving a government scholarship is a young researcher. However, the expression doctoral students is used in the paper.
} 
subject-related grade average, for example GPA - cumulative grade point average, see Robbins et al., 2004) and persistence (retention or the length of time a student remains enrolled at an institution towards the completion of the program of study, ibid.), and most often focusing on college or university students (e.g. Endo and Harpel, 1978; Pascarella and Terenzini, 1978; Tinto, 2004, 1997; Astin, 1999; Pritchard and Wilson, 2003; Lotkowski et al., 2004; Robbins et al., 2004; Robbins et al., 2006; Le et al., 2005; Llorens et al., 2007; Olani, 2009; Kim et al., 2010). Some earlier studies (Endo and Harpel, 1978; Pascarella and Terenzini, 1978; Tinto, 2004; 1997; Astin, 1999) clearly emphasized the importance of students' social integration into the educational institution and peer group (classroom), using frequency and strength measures of social interactions (such as studentfaculty interaction: frequency of formal interaction, frequency of informal interaction, quality of faculty advising, and helpfulness of faculty (Endo and Harpel, 1978), frequency and strength of informal student-faculty relationships (Pascarella and Terenzini, 1978). Both studies provided evidence that interaction is a valid and significant predictor of educational outcomes varying from academic performance to satisfaction with educational experience. Pascarela and Terenzini (1978: 183) showed that "... the frequency of student-faculty informal interactions focusing on intellectual or course-related matters had the strongest positive association with academic performance and intellectual development. Interactions for the purpose of discussing students' career concerns had the strongest association with self-perceived personal growth." Tinto (2004) focused more on school persistence, but nevertheless stressed the influence of social integration within the classroom on persistence.

Later studies, especially a growing number of meta-analyses, have left out the interactional measures and focused more on other influences or precedents of educational success. Lotkowski et al. (2004) and Robbins et al. (2004) studied possible predictors of college performance and retention, performing metaanalyses of 109 studies and combining theories and approaches from educational and psychological fields, namely the educational persistence models and motivational theories. They formulated the following nine broad constructs of psychosocial and study skill factors (PSFs): achievement motivation, academic goals, institutional commitment, perceived social support, social involvement, academic self-efficacy, general self-concept, academic-related skills, and contextual influences (including financial support, size of institutions, and institutional selectivity). None of their factors were interactional. As regards college performance (GPA - cumulative grade point average), the best predictors for GPA were academic self-efficacy and achievement motivation (as well as academic success on the previous education level), whereas other psychological and study skill factors and contextual factors were not strong predictors of academic performance.

On the basis of their meta-analysis, Le et al. (2005) constructed a student readiness inventory, an instrument that combines motivational, academic related 
skills (study skills, problem-solving skills, communication skills and emotional control skills), social engagement (teamwork - the ability to work collaboratively with others, social activity - the ability to develop and maintain relationships with others, and social connection - the extent to which the student feels connected to the social environment and has social resources) and self-management skills. The instrument was tested against academic performance and retention (Robbins et al., 2006). Their study indicated that measures of motivational, self-management, and social engagement factors were all related to academic performance and retention. The academic-specific motivational measures (Academic Discipline and Commitment to College) were better predictors of academic performance and retention than general measures (the influence weakened after controlling for prior academic achievement, self-management and study skill reports). A similar scale the College Learning Effectiveness Inventory (CLEI) (Kim et al., 2010) - has emerged, although there is little evidence of its predictive abilities as regards educational outcomes (Bratton Yeager, 2009).

The influence of personal networks (discussion partners within the last year) and social support (perceived ISEL - interpersonal support evaluation list by Cohen) on study attainment (years to complete the diploma) was studied by Eggens et al. (2008). The support variables had no effect on educational outcome, whereas the network variables significantly predicted attainment (the number of network members, the average age of the network members and the network density). As the authors used very general measures of social networks and social support, it is not surprising that perceived social support had no effect on educational outcome and that only network size and density had a significant effect. Our assumption is that social support and personal networks would probably explain more variability in attainment if the measures were directed at specific, education-oriented, social support and personal networks.

Given the lack of attention of educational research to the possible connection between students' success in education and their social environment and its supportive role, there is a clear need to examine the influence of social support and personal networks on educational performance. Further, there is some research about the performance of doctoral students (Green and Bauer, 1995; Austin, 2002; Hemlin et al., 2004; Paglis et al., 2006; papers coming from the INSOC - International Network on Social Capital and Performance, e.g. Ziherl et al., 2006; Coromina et al., 2008; Matelič et al., 2007; Kogovšek et al., 2004) and factors that influence their educational outcomes (in the case of doctoral students these can be: the number of completed exams, the number of published papers or other kinds of academic achievements, years to complete the doctoral degree or dropout). The factors that explain a significant proportion of variability in outcomes of college or university education (e.g., performance at a lower level, socioeconomic status of parents) may lack predictive power at the level of doctoral education as these students represent a far less heterogeneous group than students at lower levels. All of them have shown an excellent performance at the university 
level since this is a condition to commence doctoral studies and probably most of them have developed substantial study skills. They may differ in their motivation to obtain the doctoral degree and this is the psychological factor we have included in our model. Matelič et al. (2007) and Ziherl et al. (2006) have already shown that an internally-oriented motivation (interest in research and autonomous work) for doing doctoral research has a positive effect and an externally-oriented motivation (doing the $\mathrm{PhD}$ for prestige and better chances of later employment) had a negative effect on their academic performance (also see Green and Bauer, 1995; Paglis et al., 2006).

\section{Predicting job performance (academic performance)}

Not surprisingly, there is a connection between academic performance and job performance, as pointed out by Robbins et al. (2004) and motivational constructs, very similar to academic self-efficacy. As regards work performance, a number of theories explain positive or negative precedents and consequences of job performance, burnout and engagement. The Job Demands-Resources model (Xanthopoulou et al., 2007; Bakker and Demerouti, 2007) is a combined model that seeks to explain how health impairment (e.g., burnout) and motivation (e.g., work engagement) may be produced as a consequence of two sets of working conditions: job demands and job resources. Job demands are physical, psychological, social, intellectual or organizational aspects of the job that require continuous efforts or skills. They are associated with certain physiological and/or psychological costs. Job resources are aspects of the job (physical, psychological, social, intellectual or organizational aspects) that are functional in achieving work goals, reduce job demands or stimulate personal growth. Job resources may be located at the level of the organization, interpersonal and social relations (e.g., supervisor and co-worker support, team climate), the organization of work (e.g., role clarity, participation in decision-making), or at the level of the task (e.g., skill variety, task identity, task significance, autonomy, performance feedback). Job resources, especially social support, may buffer the influence of job demands on negative health outcomes such as burnout. A high quality relationship with the supervisor or mentor may diminish the influence of job demands or job burden. Something similar is true for job autonomy. Social support is obviously a resource related to work performance. Instrumental support, specifically related to job demands, obtained from colleagues can help get work done in time, and may mediate the influence of job overload. The stress-buffering hypothesis states that social support protects employees, or doctoral students in our case, from the pathological consequences of stressful experiences (Cohen and Wills, 1985). Moreover, constructive, specific and accurate feedback would help a person perform more effectively and also improve communication between employee and supervisor (or between doctoral student and supervisor). Appraising a good 
performance and expressing issues that need improvement in a positive manner would help maintain motivation and prevent work problems. The final proposition of the JD-R model is that job resources particularly influence motivation or work engagement when job demands are high (ibid.), therefore indicating that job resources (a high quality relationship with the supervisor and effective social support from colleagues) are crucial for doctoral students.

The JD-R model has been empirically tested in different settings, varying from organizational context (Xanthopoulou et al., 2007) to educational context (Llorens et al., 2007; Schaufeli et al., 2002). Xanthopoulou et al. (2007) showed the mediating role of job resources on the relationship between job demands and burnout. Llorens et al. (2007) tested the reciprocal nature of the relationship between the constructs outlined in the JD-R model in a longitudinal experimental setting. Their findings show reciprocal relationships between task resources, efficacy beliefs, and engagement. Efficacy beliefs play a mediating role between task resources and engagement. Engagement increases efficacy beliefs, which in turn increase task resources over time. The explanatory power of burnout and engagement on academic performance was already tested in a university setting by Schaufeli et al. (2002) in a cross-national survey (Spain, Portugal and the Netherlands). They examined, more specifically, academic performance (i.e., the ratio of passed exams in the previous term relative to the total number of exams). In all countries, academic performance was negatively related to burnout and positively related to engagement.

If we consider activities leading towards the completion of the doctoral thesis (presenting scientific results of doctoral students' efforts at conferences, publishing papers in high quality journals) as work or job performance, then we can operationalize students' individual characteristics (motivations) and characteristics of the interpersonal and social environment (relationship with the supervisor, support received from the supervisor and research group) as job resources. The JD-R model has already been used to explain university education outcomes (Schaufeli et al., 2002) and we adapt the model to explain variability in the academic performances of doctoral students. In the following paragraphs previous findings about factors that explain doctoral student performance in Slovenia are briefly outlined.

As shown by Matelič et al. (2007) and Ziherl et al. (2006), the relationship between a doctoral student and their supervisor influences the performance of the doctoral student (constructive, specific and accurate feedback - professional advice has a positive effect on performance, while hindering autonomy has a negative effect). Not surprisingly, the supervisors' own scientific performance (cumulative) also has a positive effect on the performance of a doctoral student. Further, when considering the structural properties of doctoral students' research groups in terms of social capital, Ziherl et al. (2006) showed that a doctoral student's performance was strongly correlated with network size, the number of 
different institutions (from which research group members come), the number of the doctoral student's structural holes and group cohesion.

To summarize, the focus of this paper is the performance of doctoral students. We try to explain their academic performance, measured by the number of publications in all years enrolled in the doctoral study, with psychological resources (work motivation) and social resources (social support and personal networks), while controlling for years spent at the university.

\section{Method}

\subsection{Data}

The questionnaire on which the analysis in the paper is based (de Lange, 2005; Coenders et al., 2007) was created by the INSOC (International Network on Social Capital and Performance) research group. The data collection in Slovenia was carried out in several steps. Firstly, 236 young researchers (doctoral students) in their third year of doctoral study in the 2002/03 academic year were identified on the basis of the Ministry of the Republic of Slovenia for Science, Education and Sport database. Secondly, the doctoral students' official supervisors defined their students' research group on the basis of three name generators and provided contact details of the network members (the name generators are given in Appendix 1). 204 supervisors responded and, owing to additional refusals (e.g., not having enough time, concerns about data security), 190 research groups were defined. Thirdly, young researchers, their supervisors and members of the research groups filled in a web-based survey (after an initial announcement letter sent by ordinary mail, one invitation letter and two reminders were sent by email). Out of the 194 contacted doctoral students, 117 responded to the survey (a response rate of $60 \%$ ). In the paper the responses of doctoral students are analyzed as egocentered networks. In previous studies the analysis of duocentered networks (doctoral student - supervisor) was considered (Coromina et al., 2008) and the analysis of whole research group networks was presented (Ziherl et al., 2006) on a much smaller number of units.

\subsection{Measures}

Academic performance was measured by the doctoral students' self-reports on their publishing activities in the last three years, ranging from peer-reviewed international journals to internal research reports and conference presentations since a comparable and reliable bibliographic system across the participating countries in the INSOC project was not available. The publications were classified in four major groups: 
1. articles in international journals (with/without reviewers), books/chapters in books - with reviewers (int_art);

2. articles, papers in proceedings - with reviewers (pub_rev);

3. articles, books/chapters in books, papers in proceedings, internal research without reviewers (pub_norm); and

4. participation at international/national conferences/workshops - with a presentation or poster (pap_conf).

Since academic publications are often valued differently, we decided that some types of publications should have a larger weight. Based on the discussion of the different indices of the performance of doctoral students in the INSOC group (Coromina, 2006), an index of doctoral students' performance was defined as:

performance $=2 *$ int_art $+2 *$ pub_rev + pub_norm + pap_conf.

Work motivation was measured with the following six indicators:

1. I'll do overtime to finish a job, even if I'm not paid for it

2. The greatest satisfaction in my life comes from my job

3. The most important things that happen to me involve my work

4. Some activities are more important to me than work

5. To me, my work is only a small part of who I am

6. Most things in life are more important than work

An ordinal response scale was used ranging from 1 - completely disagree to 7 - completely agree. A Likert scale was calculated using the average of all indicators. Items 4, 5 and 6 were reverse-coded before computing the Likert scale of work motivation.

Social support and personal networks inside the predefined research groups by the supervisors is measured with the following indicators measuring the strength of social interactions that predict the doctoral students' performance described in Sections 2 and 3:

1. Consider all work-related problems you have had during the past year (that is, since 1 November 2002) and for which you couldn't find a solution yourself. How often have you sought advice from each of your colleagues on the following list? (advice)

2. Consider all situations in the past year (that is, since 1 November 2002) in which you co-operated with your colleagues, e.g., working on the same project, solving problems together and so on. Minor advice does not belong to this type of co-operation. How often have you been co-operating with each of your colleagues? (co-operation)

3. We would like to know with which colleagues you engage in social activities outside the work context, e.g., doing sports, social or cultural activities. [Attention: a lunch together on a work day and activities 
organized by your organization, such as following courses, attending formal organized dinners or participating at a conference do not belong to this type of social activities!] How often in the past year (that is, since 1 November 2002) have you been attending social activities outside the work context with each of your colleagues? (socializing)

4. Suppose you are confronted with serious problems at work (e.g., a lack of motivation, a problematic relationship with a colleague). With which of your colleagues would you discuss these problems? (emotional)

For the first three indicators the social support provision was assessed using the following scale: don't know the person, not in the past year, once last year, several times a year, about monthly, several times a month, weekly, several times a week, daily. For the fourth indicator, the following scale was used: certainly not, probably not, probably yes, certainly yes.

The variables included in the factor model based on the above indicators are the number of persons with whom the doctoral student gets along well inside the research group (socializing) ${ }^{5}$; the number of persons who the ego would ask for emotional support (persons marked "probably yes" or "certainly yes" were summed); the sum of advice contacts; and the sum of co-operation contacts ${ }^{6}$. The scree plot (in Appendix 2) shows one dimension. Factor loadings were obtained by principal axis factor analysis. The obtained factor explains $59 \%$ of the variability. The Kaiser-Meyer-Olkin Measure of Sampling Adequacy (.804) and the Bartlett's Test of Sphericity $(\mathrm{p}<.001)$ indicate that the factor model is appropriate.

Table 1: Social support and social networks - loadings obtained by the principal axis factor analysis.

\begin{tabular}{lc}
\hline Indicator & Factor loadings \\
\hline Number of persons with whom the ego gets along well & .769 \\
Number of persons the ego would ask for emotional support & .744 \\
Sum of advice contacts & .761 \\
Sum of co-operation contacts & .798 \\
\hline
\end{tabular}

Factor scores are used in the subsequent analysis to measure social support and personal networks.

\footnotetext{
${ }^{5}$ The question used was In a work situation it can happen that members of a research group do not get along with each other. It could be that you have a row with some members of the research group, it could be that you try to avoid contact with particular colleagues, that you can't get on with someone etc. With which members of the research group can't you get along? The scale was from 1 (very badly) to 7 (very well). Persons marked with 6 or 7 were summed.

${ }^{6}$ The scale for advice and co-operation contacts was an eight-point scale: daily - a few times a week - weekly - a few times a month - about once a month - a few times a year - once last year not in the last year These values were summed across all persons. Therefore, these two indicators include the frequency of contact and network size.
} 
Years at department was used as a control variable in the regression model to predict the doctoral students' academic performance.

\section{Results}

Work motivation $^{7}$ and social support and personal networks factors were used in a multiple regression model to predict academic performance, controlling for years spent at the department.

Table 2: Results of the regression model.

\begin{tabular}{lccccc}
\hline & $\begin{array}{c}\text { Unstandardized } \\
\text { coefficients }\end{array}$ & Std. Err. & $\begin{array}{c}\text { Standardized } \\
\text { coefficients }\end{array}$ & $\mathrm{t}$ & $\mathrm{p}$-value \\
\hline Constant & -2.566 & 7.135 & & -0.360 & .720 \\
Social support and & 4.302 & 1.453 & .267 & 2.961 & .004 \\
personal networks & & & & & \\
Work motivation & 2.397 & 1.109 & .195 & 2.161 & .033 \\
Years at department & 3.627 & 1.707 & .191 & 2.125 & .036 \\
\hline
\end{tabular}

The proportion of explained variance is 0.136 . As the regression model shows, the social support and personal networks factor has the largest and a positive regression coefficient, indicating that work resources originating from the social environment of the doctoral student have a strong positive effect on their academic performance. Work motivation as an individual resource has a weaker but still significant effect on performance.

\section{Discussion and conclusion}

The academic performance of doctoral students, measured as the cumulative weighted average of the number of different publications over years, can be seen as an educational outcome on one hand and as a job performance on the other. Therefore, we can rely on theories and models from both fields in the search for possible factors that predict academic performance (see Lotkowski et al., 2004; Robbins et al., 2004; Eggens et al., 2008 for the educational field, and Xanthopoulou et al., 2007; Bakker and Demerouti, 2007 for the JR-D model).

Motivation has proven to be one of the most consistent individual predictors of educational success. We used work motivation as an individual characteristic that should explain some variance in the doctoral students' cumulative publication

\footnotetext{
${ }^{7}$ Several other motivational scales were also tested (Likert scales or averages of motives for pursuing the $\mathrm{PhD}$, trust in the network members, attitude to publishing, relationship with the mentor, attitude to work, work motivation, attitude to the $\mathrm{PhD}$ ).
} 
records. Our results generalize the findings from college and university studies (e.g., Pritchard and Wilson, 2003; Lotkowski et al., 2004; Robbins et al., 2004; Robbins et al., 2006; Le et al., 2005; Llorens et al., 2007; Olani, 2009; Kim et al., 2010) to doctoral studies. Indeed, work motivation is a significant predictor of students' performance at any given level. Social factors such as social support and personal networks (both work-oriented) have been neglected in educational models or measured as general perceived support and general perceived social inclusion apart from a few very early papers (e.g. Endo and Harpel, 1978; Pascarella and Terenzini, 1978; Tinto, 2004; 1997; Astin, 1999). In our study, the effect of the social factor, assessed as an interactional index, is significant in predicting the academic performance as shown at the undergraduate level in the abovementioned early papers and in Eggens et al. (2008).

As shown in this paper, doctoral student performance can be conceptualized as a job outcome, and work-oriented social support and personal networks can be operationalized as social job resources. Doctoral students who have better social job resources, more job-oriented social support from their supervisor and colleagues, get along well with the research group and can even find emotional support within the workplace should be better off than doctoral students with weak social resources. Given the results of our analysis, job-oriented social support and personal networks is a stronger predictor of doctoral student academic performance than work motivation, after controlling for years spent in the department. The application of the JD-R model (Xanthopoulou et al., 2006; Bakker and Demerouti, 2007) to doctoral studies was quite successful.

A linear regression analysis is used in our study. However, both factors associated with doctoral student academic performance are probably not linear in nature (more motivation and more job resources will not always yield a better academic performance) but are more complex. Some doctoral students may be very motivated and have excellent study skills, but do not receive much support from their supervisors or colleagues. Some others might have a conflictive or ambiguous relationship with their supervisors, but compensate the lack of support from their supervisor with support from their colleagues. Other doctoral students might be more vivacious, more outgoing, have an excellent relationship with everybody, but lack the motivation to work systematically on demanding job tasks, and so on. This probably accounts for the relatively poorly explained variance in academic performance (13.6\%). Therefore, a typology of doctoral students according to different (successful and unsuccessful) combinations of individual and social determinants (of the supervisor and research group) is a complement to this study (see Kogovšek et al., 2011 in this issue).

Further, given the strength of the individual and social predictors of academic performance and the finding that social predictors explain more variance than individual factors, one should even more closely examine the characteristics of the supervisor and research groups. Perhaps the performance of a doctoral student depends more on the academic environment (research group, see Ziherl et al., 
2006) than we anticipate and the selection procedure for positions of doctoral students should focus even more on the characteristics of a potential supervisor and their research group. When researching complete research group networks, the problem is the non-response of some members of the group which results in a huge decrease in the original sample of doctoral students.

\section{References}

[1] Astin, A.W. (1999): Student involvement: A developmental theory for higher education. Journal of College Student Development, 40, 518-529.

[2] Austin, A.E. (2002): Preparing the next generation of faculty. The Journal of Higher Education, 73, 94-122.

[3] ARRS (2011): Pravilnik o postopkih (so)financiranja, ocenjevanja in spremljanju izvajanja raziskovalne dejavnosti. URL: http://www.arrs.gov.si/sl/akti/prav-sof-ocen-sprem-razisk-dej-260111.asp.

[4] Bakker, A.B. and Demerouti, E. (2007): The job demands-resources model: State of the art. Journal of Managerial Psychology, 22, 309-328.

[5] Bratton Yeager, M. (2009): A Cross-Validation Study of the College Learning Effectiveness Inventory (CLEI). An Abstract of a Dissertation. Manhattan, Kansas: Kansas State University.

[6] Cohen, S. and Wills, T.A. (1985): Stress, social support, and the buffering hypothesis. Psychological Bulletin, 98, 310-350.

[7] Coenders, G., Ferligoj, A., Coromina, L., and Capó, A. (2007): Design and evaluation of a Web survey for the social network data. In Loosveldt, G., Swygedouw, M., and Cambré, B. (Eds.): Measuring Meaningful Data in Social Research, Leuven: Acco, 233-255.

[8] Coromina, L.I. (2006): Social Networks and Performance in Knowledge Creation. An Application and a Methodological Proposal. PhD dissertation. Girona: University of Girona.

[9] Coromina, L.I., Guia, J., Coenders, G., and Ferligoj, A. (2008): Duocentered networks. Social Networks, 30, 49-59.

[10] De Lange, D. (2005): How to Collect Complete Social Network Data? Nonresponse Prevention, Nonresponse Reduction, and Nonresponse Management based on Proxy Information. Unpublished doctoral dissertation. Belgium: Ghent University.

[11] Eggens, L., van der Werf, M.P.C., and Bosker, R.J. (2008): The influence of personal networks and social support on study attainment of students in university education. Higher Education, 55, 553-573. 
[12] Endo, J.J. and Harpel, R.L. (1978): The effect of student faculty interaction on students' educational outcomes. Research in Higher Education, 16, 115136.

[13] Green, S.G. and Bauer, T.N. (1995): Supervisory mentoring by advisers: relationships with doctoral student potential, productivity and commitment. Personnel Psychology, 48, 537-561.

[14] Hemlin, S., Allwood, C.M., and Martin, B.R. (2004): Creative Knowledge Environments. The Influences on Creativity in Research and Innovation. Northampton, MA: Edward Elgar Publishing.

[15] Kim, E., Newton, F.B., Downey, R.G., and Benton, S.L. (2010): Personal factors impacting college student success: constructing college learning effectiveness inventory (CLEI). College Student Journal, 44, 1-112.

[16] Kogovšek, T., Ferligoj, A., Matelič, U., and Hlebec, V. (2004): Social Ties of Doctoral Students in Slovenia as Social Capital. Portorož: SUNBELT conference contribution.

[17] Kogovšek, T. Hlebec, V., and Ferligoj, A. (2011): From busy bees to science geeks and party animals: A typology of Slovenian doctoral students. Metodološki Zvezki, 8, 121-136

[18] Le, H., Casillas, A., Robbins, S.B., and Langley, R. (2005): Motivational and skills, social, and self-management predictors of college outcomes: constructing the student readiness inventory. Educational and Psychological Measurement, 65, 482-508.

[19] Llorens, S., Schaufeli, W., Bakker, A., and Salanova, M. (2007): Does a positive gain spiral of resources, efficacy beliefs and engagement exist? Computers in Human Behavior, 23, 825-841.

[20] Lotkowski, V.A., Robbins, S.B., and Noeth, R.J. (2004): The Role of Academic and Non-Academic Factors in Improving College Retention. ACT Policy Report.

[21] Matelič, U., Mali, F., and Ferligoj, A. (2007): Kreativno okolje in uspešnost mladih raziskovalcev. Družboslovne Razprave, 23, 71-94.

[22] Olani, A. (2009): Predicting first year university students' academic success. Electronic Journal of Research in Educational Psychology, 7, 1053-1072.

[23] Paglis, L., Green, S.G., and Bauer, T.N. (2006): Does adviser mentoring add value? A longitudinal study of mentoring and doctoral student outcomes. Research in Higher Education, 47, 451-476.

[24] Pascarella, E.T. and Terenzini, P. (1978): Student-faculty informal relationships and freshman year educational outcomes. Journal of Educational Research, 71, 183-9.

[25] Pritchard, M.E. and Wilson, G.S. (2003): Using emotional and social factors to predict student success. Journal of College Student Development, 44, 1828. 
[26] Robbins, S.B., Lauver, K., Le, H., Davis, D., Langley, R., and Carlstrom, A. (2004): Do psychosocial and study skill factors predict college outcomes? A meta-analysis. Psychological Bulletin, 130, 261-288.

[27] Robbins, S.B., Allen, J., Casillas, A., Peterson, C.H., and Le, H. (2006): Unraveling the differential effects of motivational and skills, social, and selfmanagement measures from traditional predictors of college outcomes. Journal of Educational Psychology, 98, 598-616.

[28] Schaufeli, W.B., Martínez, I.M., Pinto, A.M., Salanova, M., and Bakker, A.B. (2002): Burnout and engagement in university students. A cross-national study. Journal of Cross-Cultural Psychology, 33, 464-481.

[29] Tinto, V. (2004): Leaving College: Rethinking the Causes and Cures of Student Attrition. Second edition. Chicago: University of Chicago Press.

[30] Tinto, V. (1997): Classrooms as communities: Exploring the educational character of student persistence. Journal of Higher Education, 68, 599-623.

[31] Xanthopoulou, D., Bakker, A.B., Dollard, M.F., Demerouti, E., Schaufeli, W.B., Taris, T.W., and Schreurs, P.J.G. (2007): When do job demands particularly predict burnout? The moderating role of job resources. Journal of Managerial Psychology, 22, 766-786.

[32] Ziherl, P., Iglič, H., and Ferligoj, A. (2006): Research groups' social capital: a clustering approach. Metodološki Zvezki, 3, 217-237.

\section{Appendix}

\section{Name generators for measuring research group membership}

Phase 1 (June - Sept. 2003): The doctoral student's research group was defined by his/her supervisor.

1. Name all the teaching assistants or doctoral assistants whose research is mainly under your supervision.

2. Name all the researchers who you have not named before and for whom you are formally the mentor and who work on or participate in a research project in which you also participate.

3. Name your colleague professors, senior researchers, junior researchers or people working in the private sector with whom you substantially work together on those research projects in which $\mathrm{PhD}$ student is involved.

Phase 2 (Jan. - April 2004): Social relationships were measured among all members of the research group (complete networks) and between the doctoral student and their research colleagues (egocentered networks). 
2. Scree plot of indicators of social support and personal networks

Scree Plot

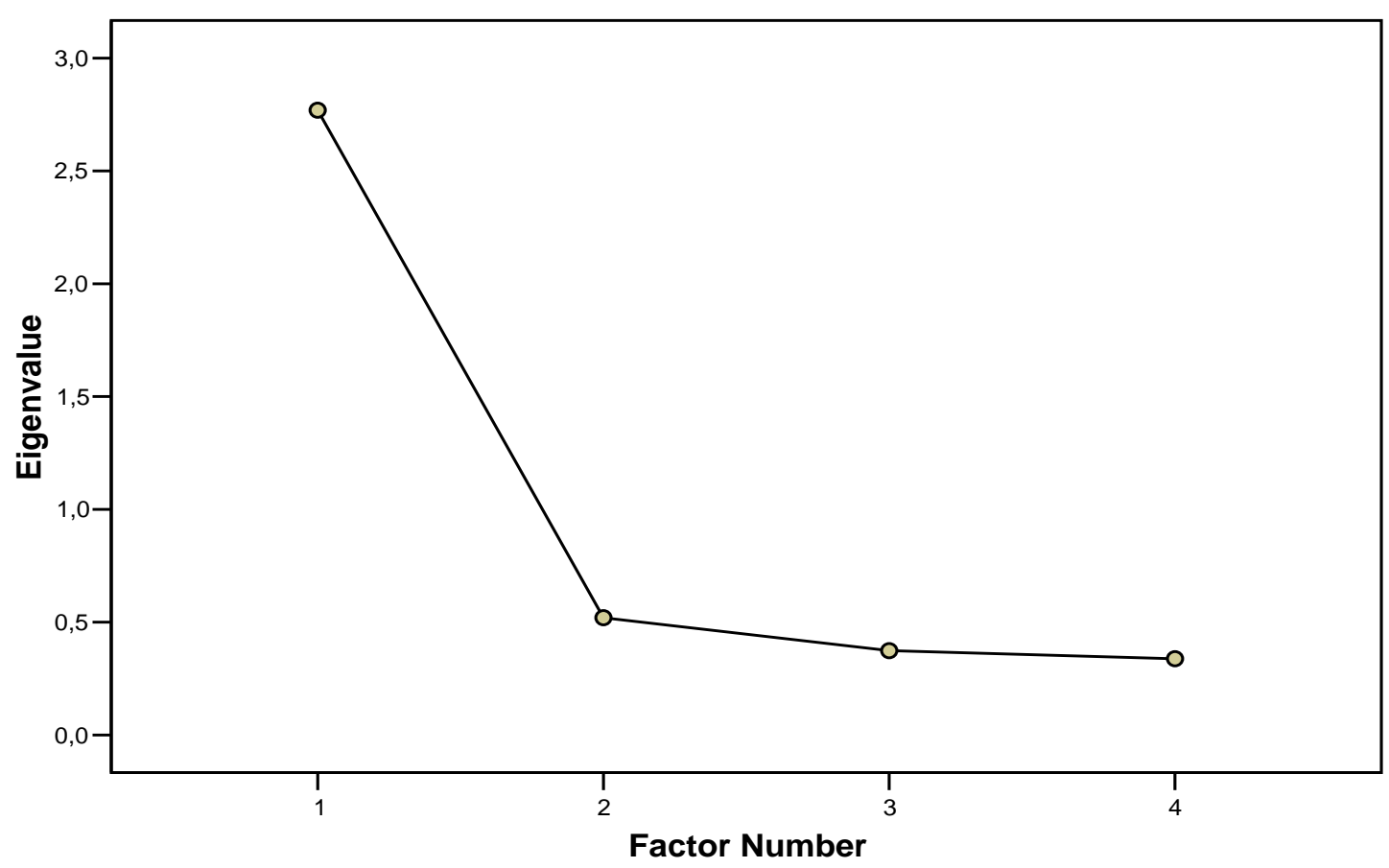

